\title{
Criminological Characteristics of Drug Addiction in the Republic of Kazakhstan: Basic Concepts, Signs and General Approaches to Their Assessment
}

\author{
Fetkulov A. K. ${ }^{1}$, Karzhasova G. B. ${ }^{1}$, Nurpeisova A. K. ${ }^{1}$, Kopbulov R. A. ${ }^{1}$, Baikenzhina K. A. ${ }^{1}$ \& Khanov T. A. ${ }^{1}$ \\ ${ }^{1}$ Karaganda Economic University of Kazpotrebsoyuz, Karaganda, Kazakhstan \\ Correspondence: Fetkulov A. K., Karaganda Economic University of Kazpotrebsoyuz, Karaganda, Kazakhstan.
}

Received: July 10, 2019

Accepted: July 29, 2019 Online Published: August 1, 2019

doi:10.5539/jpl.v12n3p40

URL: https://doi.org/10.5539/jpl.v12n3p40

\begin{abstract}
The relevance of the study is due to the need to consider such antisocial social phenomenon as "narcotism", which includes two components - "drug addiction" and "drug business". The researchers came to the conclusion that the concept of narcotism itself has not yet acquired an unambiguous or more or less well-established semantic status, and does not have wide recognition in international legal acts and documents of authoritative international organizations. In foreign vocabulary, the concept of "narcotism" is difficult to differentiate and separate from the concept of "drug addiction". Therefore, it is necessary to achieve the highest possible consistency in approaches to understanding the essence of this phenomenon.

The content of the article is aimed at identifying the key point denoting the main core around which complex processes are taking place in the desired field related to the concept of drug addiction. Reflecting and arguing, the authors, in essence, were based on an analysis of a well-known range of historical, theoretical information, international legal and national regulatory documents, using the methods of critical analysis, synthesis and comparison of theoretical and legal sources. This made it possible to consider the phenomenon under study from the standpoint of different conceptual approaches.

The article revealed that drug addiction affects the widest range of social problems - from deviant social behavior to national security issues. The attention is focused on the fact that drug addiction from the position of law is characterized as an antisocial social phenomenon associated with the illegal consumption and distribution of drugs, their appearance and the existence of goods and services in consumer circulation. A basic definition has been formulated that outlines the scope or distribution of narcotism. It was concluded that "narcotism" should be a differentiated designation of a negative social phenomenon and contain a description of the whole diversity of social manifestations and processes that are directly related to drugs that are in a state of contradiction with the interests of society. In turn, drug trafficking, while remaining the largest component of drug addiction, is its most dynamic part. The last sign is largely associated with a direct effect - the drug business, which is a generating or producing principle in narcotic drugs. The materials of the article are of practical value for researchers and law enforcement officials dealing with the problems of drug addiction and narcotism.
\end{abstract}

Keywords: drug addiction, drugs, drug business, narcotic drugs, psychotropic substances, illicit trafficking

\section{Introduction}

The study of the nature of narcotism, the system of determination of this phenomenon allows us to raise the question of the substantial dependence of the system of preventive measures in this area on measures of a general economic nature capable of solving the problems of social and economic relations in society. Of course, the implementation of such measures can actually influence the creation of prerequisites for significant positive changes in the confrontation of the state and society with many other negative phenomena. However, in any case, the solution of a specific group of problems associated with drug trafficking and abuse will depend on how competently it is possible to determine the totality of special criminological measures, the implementation of which would allow stabilization of a negative social phenomenon and a real limitation of its impact on society significant processes.

Drug addiction is an antisocial social phenomenon that creates a threat to people's health, negatively affects the nation's gene pool, destabilizes the situation in the country, and undoubtedly represents a danger to the national 
security of the country. The Law of the Republic of Kazakhstan of January 6, 2012 "On the National Security of the Republic of Kazakhstan" emphasizes that along with corruption and illicit trafficking in weapons, illicit drug trafficking contributes to decrease in the degree of protection of national interests (Law of the Republic of Kazakhstan dated January 6, 2012 "On the National Security of the Republic of Kazakhstan").

President of the Republic of Kazakhstan N.A. Nazarbayev, in his book The Critical Decade, devoted a whole section to this issue, which is called the "Special Attention Zone". According to the head of state, "Recently, the situation with drug addiction in Kazakhstan is constantly becoming more complicated and in the near and short term will undoubtedly become one of the main problems of ensuring national and state security." (Nazarbayev, 2003; Niranjan, D. S. (2016).

According to the UN and the IMF, the annual amount of profits from illicit drug trafficking in the world is about 600 billion dollars or $7.6 \%$ of world trade. In addition, each year legalizes up to $\$ 1.5$ trillion from the drug trade, which corresponds to $5 \%$ of the value of the global gross product and, in essence, is evidence that another independent area has emerged within the shadow economy, which is called the economy of drug trafficking: today, $70 \%$ of the money in the hands of criminal gangs is derived from the drug business. Operations with drugs bring from 300 to $2000 \%$ of profits, which makes them attractive for both transnational criminal organizations and local groups of criminals, whose goal is to maximize profits in a short time (Data on income from the drug business).

The problem of drug addiction in Kazakhstan, as in any other country, raises concerns that require improving the system of state and public counteraction to drug addiction and drug trafficking in the Republic of Kazakhstan, with the aim of implementing a unified and balanced policy in the sphere of drug trafficking.

\section{Materials and Methods}

Before proceeding to the analysis of the criminological characteristics of drug addiction, as, indeed, of any other negative social phenomenon, it is necessary to determine the main definitions being operated on and, above all, the concept of "narcotism" and other definitions associated with it. This is especially true also because the concept of narcotism itself has not yet acquired an unambiguous or more or less well-established semantic status, and, moreover, does not have wide recognition in international legal acts and documents of authoritative international organizations. The latter is unlikely to occur at all, since in English, German or French vocabulary the concept of "narcotism" is difficult to differentiate and separate from the concept of "drug addiction". Therefore, disputes and arguments about the definition of "narcotism" are important, first of all, and perhaps only for the theory of legal sciences and the practice of combating crime and other negative social phenomena of post-Soviet states. The latter is explained by the fact that the beginnings of scientific interest associated with the definition of this, as well as other concepts in the field of drug consumption and distribution, start counting from the 20s to the time of the collapse of the USSR, they had already become serious issues for scientific discussions, which are now continuing at the national level, theoretical thought of the sovereign states of the community.

Despite a certain autonomy in the development of criminological and criminal law sciences, there is a need for their interpenetration and strengthening the independence of their own national legislative base of each country. The interests of combating crime and other negative social phenomena that threaten national and international interests, international security require taking into account the peculiarities of the transnational nature of the drug business, as well as developing and implementing joint intergovernmental countermeasures. Therefore, achieving the maximum possible consistency, primarily in approaches to understanding the essence of the phenomena and processes that make up the object and subject of theoretical and practical interest in this area, is understandable in its relevance. In addition, it was repeatedly noted the need for harmonization of national legislation and bringing it to international standards (Khanov, Fetkulov \& Nurpeisova, 2014; Villalobos, J. V. (2018).

At the same time, one cannot disregard the significance of such clarity for other countries (non-CIS countries) and international organizations, because in any case the purpose of such theoretical research is to improve practical activities, which, as already mentioned, in the face of the danger of the global drug market condemns countries to achieve consistency in their actions.

Perhaps the key concept, denoting, in essence, the necessary core around which many-sided and complex processes occur and develop in the required area is the concept of drugs. Without delving into the history of science and legislation, we note that the transformation of legislative and theoretical positions about the concept of "drugs", as well as "precursors", "narcotic drugs", "psychotropic substances", and now also their "analogs" occurred throughout many decades of the Soviet and post-Soviet development of Kazakhstan. At the same time, if such a transformation in the conditions of the USSR was completely dependent on union legislation, then with 
independence, international legal acts, conventions and agreements to which the republic became directly involved, being a full subject of international law, became a direct reference point.

If the republican legislation, in particular, the Criminal Code of the Kazakh SSR, as well as the criminal codes of other Union republics, provided for responsibility for certain actions with "narcotic substances", and considered psychotropic substances exclusively as potent, then with the USSR's accession to the UN conventions on drugs, 1961, 1971 and 1988. Then, in connection with the accession of the Republic of Kazakhstan in 1998 to these conventions, the terminological inconsistency between the fundamental legal acts between the national community was largely eliminated.

Currently, the basic concepts used in the UN conventions are legally enshrined in the Law of the Republic of Kazakhstan "On narcotic drugs, psychotropic substances, their analogues and precursors and measures to counter their trafficking and abuse", adopted on July 10, 1998 (hereinafter the Law). In contrast to the similar Federal Law of the Russian Federation "On Narcotic Drugs and Psychotropic Substances", adopted on January 8, 1998, the concept of "narcotics" is legally enshrined in domestic legislation. Thus, in accordance with paragraph 2 of Article 1 of the Law, "drugs of a plant, substances or drugs classified as narcotic drugs, psychotropic substances, their analogues, which represent a potential danger to public health in connection with the consequences that may be caused by their abuse, included in the List of Narcotic Drugs agents, psychotropic substances and precursors subject to control in the Republic of Kazakhstan " (Law of the Republic of Kazakhstan dated July 10, 1998 "On narcotic drugs, psychotropic substances, their analogues and precursors and measures to counter their trafficking and abuse").

Leaving a substantive analysis of the presented definitions for its presentation, we note that the medical aspect of the concept of drugs and, moreover, narcotic drugs, psychotropic substances, their analogues remained in the Law, in essence, without sufficient attention. Kazakh scientists have already written about this, that it is important to develop uniform medical and legal criteria for narcotic drugs, psychotropic substances and their analogues (Fetkulov \& Mustaeva, 2017:106-107; Hasani Hossienabadi, (2016).

The direct study of the concept of narcotism, its content and signs by Kazakhstani scientists has been paying attention for a long time, starting in 1992. This allows to have own and fairly balanced position, based on critical understanding of the known assessments and approaches used by individual researchers, who actually began to develop this problem in the 1920s. At the same time, over the years, scientific interest in the definition of the concept of drug addiction and its relationship with the definition of drug addiction has not only weakened, but on the contrary, has attracted interested and growing attention from all new and new researchers. In fact, each of those who were looking for answers to questions related to finding effective ways to overcome the problem of illegal drugs in one way or another tried to determine their own attitude to understanding what to consider as drug addiction and drug addiction, what is their similarity or difference, or here is the identity.

\section{Results and Discussion}

Discussions about the essence of these and other related concepts are unlikely to cease soon, and even more so they will increase with the further almost universal aggravation of the problems of overcoming drug addiction and drug business in the world. Nevertheless, there remain two of the most important questions, the clarification of which in many respects should contain answers about the meaning of the sought-after definitions:

1) for what purpose, and with what semantic content the word "narcotism" was put into scientific and practical use;

2) what is the etymological meaning from the theoretical point of view, as well as what practical functional role it is advisable to assign to the terminological characteristics of "narcotism".

Answering these questions, one cannot overlook the creative position of such legal researchers as T.A. Bogolyubova, E.G. Hasanov, M.M. Kadyrov, K.Sh. Kurmanov, P.N. Sbirunov, who prepared major scientific works on various problems of narcotism in the form of dissertations for the degree of Doctor of Law. Obviously, the thoughts and arguments of these authors are essentially based on an analysis of a well-known range of historical, theoretical information, international legal and national regulatory documents, mainly related to the period of the Soviet Union. At the same time, in later developments there are noteworthy manifestations of attempts at an integrated approach to the study of negative social phenomena. In any case, the importance and significance of the results of the creative work that has been completed and continues to be performed by a group of experienced experts in this area should be emphasized.

Drug addiction is a complex biopsychosocial phenomenon and is considered in science from the standpoint of different conceptual approaches. In addition to the medical aspects, which are the subject of narcology and 
psychiatry, narcotism affects the widest range of social problems - from deviant social behavior to issues of national security (Hlopushin R.). Drug addiction is a common category of law, sociology, psychology, medicine and other sciences, each of which, in accordance with its own subject and research methods, studies it (Sartaeva, 1998).

Exploring drug addiction from a legal perspective, Professor N.M. Abdirov has already stopped on the assessment of drug addiction as an antisocial phenomenon associated with the illicit consumption and distribution of narcotic drugs, their appearance and the existence of goods and services in consumer circulation. In his fair opinion, this definition as a whole seems to be acceptable as a basic one, since, it seems, quite definitely outlines the scope or manifestation of drug addiction (Abdirov, 1996).

According to some scientists, the spread of drugs is dangerous for society and in the economic sense, since it is one of the main causes of losses in the national economy of most countries (Harevich \& Bazyleva, 2004). It is necessary to agree with this point of view, indeed, narcotism undermines not only the moral, social, political, but also the economic foundations of society, thereby representing a threat to economic security, which is one of the components of national security.

Analyzing the concept of drug addiction, one cannot do without a comparative assessment of it with drug addiction, since the very mention of drug addiction is thought, first of all, it appeared that the characteristics of socially dangerous drug dealing, which were not related to medical aspects, were difficult to "squeeze" into framework of initial ideas about drug addiction. It should be emphasized that attempts to find a definition that would adequately reflect not only medical, but also legal, social and other characteristics were made by Soviet scientists. However, in the Soviet state, for many specific items, drugs and various types of treatment were "outlawed".

Moreover, over time, the prohibitive "press" of the law in relation to drugs not only did not weaken, but, on the contrary, became wider and tougher. However, this did not prevent individual researchers from trying to find a legal definition of drug addiction, and even consider the latter, not only as a disease, but also as a social phenomenon, and also include in the content of drug addiction a number of illegal actions prohibited under the fear of criminal punishment.

For the facts let's turn to the history of science and domestic legislation, as well as to international legal documents. It is difficult to trace when, for the first time, the word "drug addiction" appeared in the language of human civilization, however, it is known that the word itself originally meant a disease that has a direct connection with drug use. Practically without discussion about the expansion of the semantic format that limits drug addiction, the domestic medical science "conveyed" this concept to the beginning of the $20 \mathrm{~s}$. And later medical scientists actively worked to deepen knowledge about drug addiction. Drug addiction is a painful desire to poison your body, and on the other hand, a disease that arises from the long-term satisfaction of such attraction. Drug addiction in the first sense is psychological and physiological dependence, in the second - a disease due to its systematic consumption. Damage from drug addiction represents a significant economic burden for the state, and is associated with the costs of providing medical assistance to people suffering from drug addiction, ensuring law and order and fighting crime, as well as reducing productivity (Osetrov, 2015). Drug addiction as a disease is expressed in the pathological attraction to narcotic drugs, psychotropic substances and their analogues, as a result of addiction to them. In this semantic content, this definition is included in the encyclopedic and reference medical publications.

However, this did not mean the absence in the first half of the twentieth century of acute discussions in medicine about the content of the concept of drug addiction. Significant features and differences in approaches to this were observed in physicians of various countries, which, together with the dangerous global trends in drug addiction, prompted the World Health Organization to formulate this definition in 1952 as follows: "Drug addiction is a state of periodic and chronic intoxication harmful to rights and society caused by repeated use of the drug (natural or artificial). Its properties are as follows:

1) an irresistible desire or need to continue to take the drug and get it by any means;

2) the desire to increase the dose;

3) mental (psychological), and sometimes physical, dependence on the effects of the drug".

In this case, under the mental addiction, WHO offered to understand the state in which a narcotic drug causes a feeling of satisfaction and mental mood, which requires the periodic or constant introduction of this drug in order to achieve pleasure or avoid discomfort. Physical dependence is a state of adaptation, which manifests itself in intense physical disorders when the administration of this drug is stopped. Some scholars have noted that 
removing physical dependence on drugs gave a very low percentage of remissions, because the psychological aspect of developing and maintaining addictive behavior was ignored. Although the psychological aspect of somatic disorders of the human body has long been taken into account in medicine and in psychotherapy. It was noted long ago that with the same treatment, some patients recovered faster, others much slower (Lisetskiy \& Lityagina, 2014). At the same time, drug addiction did not necessarily imply mental illness and did not exclude sanity. As you can see, the results of studies of narcologists and psychiatrists were practically recognized by WHO, since they do not contradict the position of the latter.

It should be noted that abrupt cessation of drug use causes a violation of many body functions - "abstinence", i.e. the so-called narcotic fasting. Everyone knows that drug abuse impedes the intellectual, physical and moral development of the individual, and the negative consequences of this process inevitably affect the future generation of the country. A drug abuser is first of all a sick person, and then a criminal (Fetkulov \& Seithozhin, 2018).

Subsequent research contributed to the deepening and expansion of knowledge about this subject. True, tobacco and alcoholic beverages were often referred to as drugs, less often tea and coffee, and alcoholism was regarded as "one of the types of drug addiction." This position of physicians could not but influence the content of subsequent developments of legal scholars who studied the problems of preventing alcoholism. In particular, they proposed measures to combat alcoholism, it was considered in the context of the fact that alcoholism is a type of drug addiction. This approach was initially unpromising, since, as it turned out, the content and nature of these diseases are not identical. As it turned out from a medical point of view, "alcoholic beverages differ from narcotic substances in that physiologically human blood contains $0.01-0.03 \%$ alcohol and special enzymes for its breakdown (for example, catalase and others). Alcoholic beverages, unlike drugs, also provide an energy effect ( $1 \mathrm{~g}-7$ calories). The human body does not contain narcotic substances, as well as special enzymes for their breakdown.

In general, medicine has developed sufficiently capacious and understandable knowledge about drug addiction, as a specific disease, which lawyers successfully began to use when working out the problems of combating socially dangerous manifestations in the sphere of trafficking in illicit drugs. For some, this led to the admission that the drug addict, i.e. a person suffering from drug addiction cannot be considered as criminals, since in this case the state will conflict with the medical characteristic of drug addiction. The person who committed a criminal offense, being a drug addict, is a sick person, and his treatment consists not only in removing the withdrawal syndrome, but also in rehabilitating his psyche and mental state (Khanov, Bakischev, Fetkulov \& Nurpeisova, 2017). Here one should agree with the opinion of A.K. Idinov, who believes that in this respect it is obvious that it is necessary to step up measures to counter and take measures to counteract the spread of the threat of drug addiction. These are drug abuse prevention, drug trafficking prevention, as well as drug addiction rehabilitation. In other words, the fight against drug trafficking should be carried out in all directions, internal drug addiction and treatment and rehabilitation, as well as external - the fight against cross-border drug trafficking (Idinov, 2015).

Other researchers began to significantly expand their ideas about drug addiction, which naturally led not only to a change in content, but also in general in the nature and essence of its initial definition. Drug addiction was proposed to be conditioned in the legal aspect and considered as a negative social phenomenon of a certain content, or to link it with specific negative behavioral manifestations of a person contrary to criminal and administrative legislation. So, in accordance with the position of KI Kurmanov, "drug addiction is the commission of socially dangerous criminal actions related to narcotic drugs listed in the law in order to satisfy their illegal, antisocial, mercenary aspirations aimed at harming people's health" (Kurmanov, 1989).

Other positions are also known to science, to a certain extent similar to those presented above, but having some distinguishing features.

At the same time, another line was developing, the adherents of which adopted a completely different definition "narcotism". In the monograph "Problems of the criminal law of the fight against illicit drug trafficking" (1993), M.M. Kadyrov analyzed in detail and thoroughly the history of the emergence of this word in the scientific and practical turnover in connection with the problems of the fight against drug addiction. In his opinion, in the legal and medical literature of the 1920s, the term "narcotism" was first used in the sense of a social phenomenon that characterizes the prevalence of drug use, including morphine, cocaine, heroin, and "drug addiction" - in the narrow medical sense as the name of the disease (Kadyrov, 1993).

Thus, essentially, two different approaches were proposed in the "designation" of the definition "narcotism", where the former was associated with the designation of any drug abuse, even with the stipulated reservations, 
while the latter had to define the biological, without pathological, the pursuit of narcotic stimulation of a healthy body.

These originally proposed approaches to the definition of "narcotism" over time, of course, have undergone significant changes. Nevertheless, individual lawyers-researchers adhere to them so far. In this regard, should be called P.N. Sbirunov, who consistently and traditionally linked his own ideas about narcotism with what was determined initially. True, in his position there is one important feature related to the fact that in it he actually unites in a whole, in principle, differing approaches in defining this concept, while at the same time developing them to some extent. In the author's abstract of the doctoral dissertation, "figuring out the meaning and meaning of the term" narcotism ", it is concluded that it means the desire for anesthesia, which carries a biological basis. However, depending on the desire, the will of the subject and the social and living conditions, anesthesia can take various forms: hard pathological (use of drugs, potent substances, alcohol, etc.) or physiological (enjoying art, sports, science, etc.) ". Continuing, he defines drug addiction and "as a negative social phenomenon, due to unfavorable social conditions and the anti-social orientation of the individual, which is expressed in the non-medical intentional use of narcotic drugs that causes harm to human health and represents a danger to society." At the same time, by the term "drug addiction", this author implies "the use of narcotic drugs, which by its origin and character of manifestation is pathological" (Sbirunov, 1998).

More similar than different, primarily in assessing the starting position, one should consider the approach of some scientists who suggested using the term "narcotism" to refer to the social content of non-medical use of narcotic drugs, and the term "drug addiction" as the name of the disease. In principle, A.I. Alexeev, who, in a course on lectures in criminology published in 1998, notes that " $\ldots$ along with drunkenness and alcoholism, potent criminogenic factors, as well as negative social phenomena accompanying crime, painful addiction to drugs " (Alexeev, 1998). However, it should be noted here that he considers both narcotism and drug addiction as negative social phenomena.

The emergence of the definition of "narcotism" in the scientific and practical revolution in the fight against illicit drugs was served by well-defined social interests related to the need to prevent uncontrolled consumption of morphine, cocaine and other drugs by the population of the country, since by that time doctors had already felt the need for this the correct formulation of the study of the drug problem in its social perspective. "At the same time, the disease itself was initially established as a result of such abuse, which was given the name "addiction". Otherwise, it can be said as follows: physicians have differentiated the disease, which is dangerous for human society, determined the presence of its roots in the social sphere and sounded the alarm to the state. The latter should have responded to the situation properly. It is equally important to pay attention to the fact that from the very beginning the definition of "narcotism" was claimed as a social category or characteristic, and not as a designation of the biological or chemical properties of something.

Further, the rapid development of drug-related processes in the country demanded from the state the implementation of adequate measures not only against drug abuse, but also against specific activities related to trafficking in them, inciting others to such abuse, with the maintenance of dens for sharing opium, heroin, morphine, hashish and other socially dangerous manifestations. This naturally affected a significant semantic transformation and the definition of "narcotism" itself, as the researchers "saw" other social horizons in the field of dangerous drug treatment, and not just their abuse, although, as already noted, the legal science has hardly Attempts were made to give a legal definition of drug addiction. It seems that this is in general terms the scenario of the development of scientific research related to drug addiction.

Therefore, the approach and the development of the problems of drug addiction, implemented by L.E. Redzhepov, who defined narcotism as a social phenomenon, which includes all illegal actions related to narcotic substances (Redzhepov, 1985). More specifically and definitely, on the basis of an extensive analysis, M.M. Kadyrov, according to which narcotism means "all crimes under criminal law committed by persons against narcotic substances" (Kadyrov, 1993).

Here it should focus on the position of T.A. Bogolyubova, which is characterized by a special approach to the assessment of drug addiction. Assuming that facts relating to narcotic and toxic means are included in the concept of narcotism, it considers the use of two separate types of narcotism as the negative social phenomenon expressed in the mass withdrawal of individuals from social reality and activity into the world of surreal fantasies and illusory perception of reality arising from the use of intoxicants (Bogolubova, 1991). This definition is more socio-psychological than legal. At the same time, it is obvious that the author limits narcotism to the use of narcotic drugs and expands ideas about it at the expense of toxic drugs.

Among the latest developments in the field of drug addiction should also be mentioned the book by E.G. 
Gasanov "Drug addiction: trends and measures to overcome (on the materials of the Republic of Azerbaijan)," in which the author, based on a multidimensional analysis of drug addiction, expresses his own position on the essence of the latter. In his opinion, drug addiction is a "negative social phenomenon, including social, legal, criminological, economic, biological and environmental elements (aspects), affecting respectively social, legal, criminological, economic, biological and ecological spheres, expressed in the incidence of drug addiction and a combination of illegal acts related to drugs or committed with the aim of obtaining funds for the subsequent purchase of drugs or in a state of intoxication " (Gasanov, 1997).

These are today the main evaluation characteristics in relation to narcotism. Their analysis allows us to conclude that, despite a significant range of opinions, the prevailing position is an expansive interpretation of drug addiction, compared to the initial one, when in the early 1920s a growing social danger from drug abuse gave rise to the need for a new definition that would reflect properties and manifestations of the processes related to drug addiction. In our view, it was precisely such a task that was put before the definition by the pioneers of this idea, as which "narcotism" was proposed. Moreover, as we have already noted, it was not the etymology of the word that was originally taken into account. The term "narcotism" was intended to fulfill the function of characterizing any kind of drug abuse, which is obviously beyond the scope of medical differentiation itself. However, the rapidly developing processes in society that are directly related to drug abuse, the growth of socially dangerous manifestations on this basis, demanded an adequate assessment from the society. Thus, in our opinion, there was an increase in the relevance of social aspects that are directly related to drug addiction, which have now been associated with drug addiction. In other words, as we see it, both the expansion of ideas about the content and boundaries of drug addiction, and the search for options for the legal definition of drug addiction were dictated by social processes of aggravation in the sphere of drug trafficking and abuse. Moreover, this need existed not only in theory, but above all in practical law enforcement. Analyzing the positions of legal practitioners working in this field, it should be noted that the most widely used today is a broad understanding of drug addiction. According to Kazakhstani scientists, it should also be dismissed that the criminal law still "avoids" this term, without mentioning it. Perhaps this has the same explanation as the fact that the term "crime" also failed to "register" in the legislation.

It should also be noted that for more than seven decades, the period of more or less active use of the term "drug addiction" in the field of studying and combating illegal drugs, new terms have appeared, such as "drug trafficking", "drug trafficking", "drug business" and other which also received sufficient distribution. In this connection, there arises, in our opinion, a legitimate, not so much even for theory, as important for practice, the question of how to designate those meaningful and interrelated, covering many areas of the social: life processes, in our opinion, have long since become properties of the social phenomenon of a negative order. In other words, the question should be posed in the aspect of the objective necessity of terminological differentiation, the result of which would be the isolation of the definition, capable of covering in its own parameters the whole range of social manifestations and processes that are directly related to the so-called "illegal drug" in international practice.

Today, there is a need for one and clear term for all, to cover all those complex processes and events that occur in the social life of society, have a common nature through the connection with illegal drugs and thus represent a single negative social phenomenon, against which to be concentrated efforts of the state and society. As we see it, the definition of "narcotism" is capable of fulfilling this role with the greatest benefit today.

At the same time, first of all, one should take into account the initial social, rather than etymological, orientation with which this term was once demanded. Secondly, this social orientation itself, it seems, provoked the semantic expansion of the term as the state differentiated new socially dangerous manifestations and processes related to drugs. As a result, and thirdly, today the overwhelming majority of researchers and legal practitioners associate their ideas about narcotism, at least with the commission of so-called drug crimes. Fourthly, each of the terms used in theory and practice, whether it is "drug trafficking", "drug trafficking", "drug trafficking" and others, today is largely quite concretely differentiated and "does not reach" the designation of the phenomenon in whole

In addition, some of these terms have already received specific legislative consolidation.

It seems that a kind of quintessence of reflections, should be their own idea of narcotism, as well as other terms that appeared later and their content in terms of correlation with each other. Thus, "narcotism" in the proper sense of the word should be a differentiated designation of a negative social phenomenon and contain a characteristic of the whole diversity of social manifestations and processes that are directly related to the so-called illegal drugs, i.e. drugs that are in contradiction with the interests of society. In this case, in a natural 
way, any cultivation, production, trade and use (use) of drugs, drugs containing drugs that are the subject of the legal economy and the official relations of their subjects (these relations) both within the country and between states will be outside the scope of drug addiction. Drug addiction should be a characteristic of only a negative phenomenon. In addition, it will allow for a clearer focus on it of the opposing efforts of the state and to form clear ideas in the public consciousness of the population. Otherwise, confusion and loss of landmarks are inevitable.

Here, I think, it would be appropriate to give the opinion of N.A. Sartaeva about narcotism, presented as a result of her own monographic research, carried out under the scientific guidance of Professor N.M. Abdirov. In her opinion, drug addiction is:

1) a phenomenon that is broad in scope and rather abstract in character;

2) a complex, multidimensional phenomenon, which allows to consider it in the most varied angles. He is the butt category of law, sociology, psychology, medicine and other sciences, each of which, in accordance with its own subject and research methods, studies it (for example, the effect of drug use on the physical state of the offspring - the medical aspect, the relationship between the degree of addiction to drugs and the degree of personality degradation - the psychological aspect and others);

3) a social phenomenon that covers various stages of the historical development of society (the action of the opium poppy, as a hypnotic, was known as early as a thousand years before our era) (Hlopushin R.).

Famous Kazakhstani criminologist, professor N.M. Abdirov has already stopped on the assessment of drug addiction as an antisocial phenomenon associated with the illegal consumption and distribution of narcotic drugs, their appearance and the existence of goods and services in the consumer circulation (Sartaeva, 1998). And today, this definition as a whole seems acceptable as a basic one, since, I think, quite definitely outlines the scope of distribution or manifestations of drug addiction. However, the first clarification should relate to the subject of regulation. Considering the real processes in the field of crime and the shadow economy, in the content of the world drug processes and the development of technologies for the illegal production of narcotic drugs, we consider it necessary to differentiate between psychotropic substances and, equally important, precursors and analogues of narcotic drugs and psychotropic drugs as well as narcotic drugs. substances. Such a seemingly private question about analogues is in fact a difficult and important one. Their danger to public health served as the main basis for including the Law of the Republic of Kazakhstan "On narcotic drugs, psychotropic substances, precursors and measures to counter their trafficking and abuse" into the scope of regulation, which defined analogues as substances of synthetic or natural origin that have chemical structure and properties similar in structure and properties to the substances included in tables 1,2,3, causing a stimulating, depressive or hallucinogenic state, hazardous to health on their abuse and are not approved as narcotic drugs or psychotropic substances by this Law and UN international conventions. This confirms once again the well-known truth about the limits of public danger, which is not necessarily limited to the contours of criminal law and criminal responsibility. The category of public danger is the concrete manifestations of human behavior that create or pose a certain threat to the interests of people and public values. And this danger exists objectively, regardless of whether the criminal or administrative legislation has succeeded or has managed to give an assessment to it. What has been said, in our opinion, is an argument in favor of, having in mind narcotism, not to limit the scope of his identification only to criminal acts. Otherwise, there will be a clearly artificial, truncated definition.

In any case, it seems, the main field and specific interest of the functioning of drug addiction as a phenomenon should always be illegal drugs, and the main core, as it was originally, is to remain drug addiction, which, in essence, forms every time around itself that huge and diverse, multisectoral a tangle of socially significant (medical, economic, political, cultural, environmental, in the field of national security) problems that initiate and differentiate the existence of an independent negative phenomenon. Of particular importance are causal relationships that are directly related to drug addiction, as well as processes and manifestations that initiate the emergence and existence of illicit drugs on the consumer market, and get into the format of drug addiction. Consequently, the term "narcotism" is much broader than the term "drug addiction", because it, along with a painful addiction to drugs, includes other manifestations, such as deviant behavior, involvement in consumption, and ultimately, this circumstance determines the social danger of both (Haliullin, 2011).

Therefore, cause-and-effect relationships that have direct relevance to drug addiction, as well as processes and manifestations that initiate the emergence and existence of illicit drugs on the consumer market, acquire special significance and enter the format of narcotism. Therefore, we consider it justified to consider any drug abuse as a manifestation of drug addiction. As applied to illicit drugs, we note that, as we think, the whole "life cycle" of such drugs, starting with their cultivation, production, manufacture, processing, purchasing, storage, marketing 
and ending with the use, in other words, in our view - their " illegal trafficking "- should be the necessary content of drug addiction.

Illicit drug trafficking is a movement, rotation of these funds in the market for goods and services and covers all kinds of possible actions with drugs, chemical and biological products, raw materials, plants and their parts that can cause drug addiction. The beginning of such a movement is the emergence of a real narcotic drug or psychotropic substance in the consumer turnover of goods and services, and the end is determined by the moment of consumption, i.e. disappearances from this turnover. Such a turnover is completed at the time of consumption or use (for example, precursors), as a result, this fact itself is not included in the turnover format. It should be noted that Kazakhstan criminalizes non-medical use of drugs in public places. In contrast, in Russia, as evidenced by law enforcement practice, significantly reduced the preventive potential of criminal law in countering illicit drug trafficking and, as a result, contributes to the growth in demand for their non-medical consumption (Skuz \& Kobozev, 2011). The same group with soft (liberal) legislation includes the states of Europe: Austria, Denmark, Spain, Italy, the Netherlands, Portugal, Switzerland, Estonia. In these countries, as a rule, there is no responsibility for non-medical use of drugs, minor sanctions are provided for offenses related to cannabis products (Shalagin, 2011).

It is quite obvious that drug addiction as a social phenomenon is in a certain ratio not only with illicit drug trafficking and precursors, but also with drug business and drug addiction. This clarification, in addition to scientific and theoretical, is also of great importance for the practice of combating illicit drugs, since it allows to differentiate the main directions and the necessary countermeasures. Drug trafficking, as we think, is in the zone of narcotism, it has a decisive influence on it and is an activity that consists of a socially dangerous organized form of human behavior aimed at extracting material income from the manufacture and distribution of drugs. Here we must agree that narcotism in the modern world is a global threat to humanity. It would seem that no one should doubt that this is the number one problem that requires immediate resolution and, on the one hand, the application of the most severe measures to the organizers and active participants in the illicit drug trafficking and the associated increase in the use of drugs in our country. On the other hand, providing effective assistance to people who are addicted to drug use for non-medical purposes (Chirkov, 2013).

It is impossible, in our opinion, also to identify drug addiction with narcotism, to put an equal sign between them. The latter should remain understandable to everyone and the only characteristic of the disease associated with drug abuse. Thus, narcotism and drug addiction should remain in diverse categories, where the first differentiates a negative social phenomenon, and the second means only a disease. Therefore, they cannot be fully considered comparable categories. Perhaps, drug addiction in the context of the totality of the desired disease can be put on one side of the scale only with such a component of drug addiction as concrete indicators of drug abuse. It seems that in the ratio of drug addiction and drug addiction, the latter should be evaluated not only as the rod mentioned above, but also as a consequence of drug addiction. Based on this approach, it can be argued that drug addiction is a dangerous social and legal phenomenon consisting in the illegal, non-medical (without a doctor's prescription) use by a part of the population of narcotic drugs, psychotropic substances and their analogues, as well as in their illegal trafficking resulting in negative medical, social and legal implications (Prozumentov, 2012).

Thus, drug addiction is in the fabric of the causal relationships of drug addiction as a phenomenon, determining the influence on their specific content.

The drug business, which we define as a specific activity driven by drug addiction, is generated and exists within the scope of drug addiction, however, it is not identical to drug trafficking. The latter absorbs the drug business in itself, being in a whole and part relationship with it. On the other hand, in order to understand the essence of drug addiction and to understand the depth of the processes occurring in it, which are largely dependent on the formative effects of the drug business, it is necessary to understand the basics of organized crime in general (Fetkulov \& Zharylkasynova, 2019).

Getting the most realistic ideas about the essence of drug addiction and its components are directly dependent on the correct assessment of its criminological characteristics. In addition to those, the criminological characteristics of drug addiction are and will remain the most important tool, allowing not only to see the picture of what is happening, but mainly, on this basis, to build a forecast of the development of drug processes in the near or distant future and to make a "request" to establish optimal countermeasures. required by the state and society. However, obtaining such a characteristic is a very complex and ambiguous matter. In any case, researchers use both official statistics and their own developed tools. At the same time, the need for the latter is very acute, since official statistics, as a rule, do not allow us to have the most capacious characteristic of the phenomenon being 
studied. It should be noted here and another rule; the lack of accurate information will always require its completion, which is often realized through approximate data and emotional characteristics. The truth is, there are objective difficulties, to develop an effective methodology for the study of a particular social phenomenon is always a daunting task.

The drug situation in Kazakhstan during the past, and especially since the collapse of the former USSR, is formed under the growing influence of a complex of socio-economic, political, demographic, legal, natural-geographical, information-psychological and medical factors that have a long period of accumulation and realization operating components. It is the existence of such a powerful basis, based on multi-level and multi-degree, multiple connections of various origins in the nature of human existence, is a peculiar basis and guarantee of sustainable development in society of processes associated with the existence of illegal drugs. Naturally, in the end, this cannot but affect the aggravation of the drug situation, which is a reflection of these processes.

Included observation of the development of problems associated with illicit drugs, and personal feelings suggest that the situation associated with the abuse and illicit drug trafficking in the republic remains dangerous and complicated. Included observation of the development of problems associated with illicit drugs, and personal feelings suggest that the situation associated with the abuse and illicit drug trafficking in the republic remains dangerous and complicated. The perniciousness of drug addiction is obvious. Drug addiction as a negative social and legal phenomenon affects all spheres of social life: the physical and spiritual health of a nation, its culture, social production, the economy as a whole (Pogrebat'ko, 2018).

Unfortunately, due to the lack of adequate tools for assessing and fixing all manifestations of drug addiction, as well as the presence of significant shortcomings in the activities of the authorized state bodies, the official statistics do not reflect his real picture. According to separate surveys, official statistics differ from real indicators by several numerical orders in the direction of decrease. However, at the same time, although with a certain amount of reservations, the statistics carried out in the country helps to see the emerging trends and prospects for the development of the phenomenon. It seems that society and the state should fear not so much even the facts of the growth of quantitative indicators characterizing the official parameters of the drug situation, but the existing rates and trends of real changes in the quantitative and qualitative characteristics of drug addiction as a major negative social phenomenon.

\section{Conclusion}

The danger and complexity of the emerging drug situation today is characterized by the following circumstances:

Firstly, the existence of a huge material attractiveness of engaging in illegal drug trafficking, which is subordinated to a combination of two main laws in this case - the laws of the market and the laws of the criminal world. In turn, the latter leads to:

a) further criminalization of the population due to the involvement of the social strata that previously formed the basis of the social welfare of society (workers, employees, students, housewives, etc.) in the drug trade;

b) the formation of a very specific regional drug business, especially in the southern regions of the republic, and, moreover, often having an increasingly stronger family drug business;

c) not unsuccessful attempts by organized crime to take control of the drug trade in the country;

d) bribery and corruption in the ranks of employees of departments and services of law enforcement agencies, designed to combat drug trafficking, health officials.

Secondly, the presence of an ever-increasing flow of transit and import of drugs to Kazakhstan. This is evidenced by the emergence, and now the rapid growth, of not only traditional drugs like marijuana, hashish, heroin, but also the proportion of such non-traditional drugs for the republic, such as new psychotropic substances of synthetic origin, especially popular among minors and young people, distributed in a contactless way through the world Internet.

Thirdly, the increasing interest of foreign drug dealers to the "production" of the Kazakhstani drug market: drugs of plant origin, raw materials and precursors - substances used in the manufacture of narcotic drugs and psychotropic substances. This is evidenced by the frequent recent arrests of citizens from foreign and neighboring countries in connection with their activities in the drug business.

Fourthly, the existence of insufficient security of the state and customs borders of the republic. Today we know about significant territories of state borders that are not secured by border or customs cover, which, unfortunately, is also known to foreign drug dealer. 
Fifthly, the presence of huge plantations of wild-growing drug-containing plants in the territory of the republic, attracting the attention of both the Kazakh and international drug business. Vast reserves of raw materials for the manufacture of drugs in Kazakhstan today pose an ever-increasing threat not only for their own people, but also for the CIS countries and Europe. Relatively cheap Kazakhstani drugs of plant origin are becoming an attractive commodity item for the criminal drug markets of other countries.

Sixth, the existence of virtually unhindered availability of drugs for the purchase of their own.

Seventh, the existence of a direct link between the strengthening of the positions of narcotism and the drug business on the one hand and the increase in crime on the other. Drug addiction today is not only a breeding ground or a consequence of the influence of crime on social processes, but also such a part as the drug business in many ways substantially initiates qualitatively negative changes in it, and especially in its organized part.

The establishment of these circumstances should be attributed to the preliminary assessment of the phenomenon being studied, which is always relevant and allows you to "find" in this phenomenon its main sectors and processes that require independent study. It is this approach that creates the prerequisites for obtaining the most prominent and substantive ideas about the nature and content of the phenomenon being studied as a whole. The justification of this approach can also be justified by the fact that the study of the characteristic properties of almost every independent sector of narcotism presupposes that the researcher has a set of specific knowledge (legal, medical, psychological, biological, environmental, economic and other) and the use of specific methodological and methodological techniques and tools. The next task should be the combination of the obtained characteristics and their cumulative analysis, which will make it possible to judge the criminological characteristics of drug addiction as a negative social phenomenon as a whole.

It seems that in any case, the study of the criminological characteristics of drug addiction will be the most fruitful and substantive subject to the maximum consideration of both the common features of this negative social phenomenon and its structural components. The study showed that the largest structural components of drug addiction are drug abuse and illicit trafficking. In turn, drug trafficking, while remaining the largest component of drug addiction, is its most dynamic part. The last sign is largely associated with the direct impact of the drug business, which is a generating or producing principle in narcotic drugs.

A special aspect of the complex criminological characteristics of narcotism, in our opinion, should always be an assessment of the personality in narcotism. This aspect seems to be largely complex, since it goes beyond the traditional concepts of criminology about the identity of the offender or the subject of victimological teaching.

Taking into account all these circumstances allows us to differentiate the most important aspects in the total criminological characteristics of drug addiction as a complex negative social phenomenon. At the same time, a special significance and an independent place in the modern characteristic of a phenomenon in the republic constitute such significant sectors of it that could be presented in the form of the following evaluation categories:

- drug abuse as a driving force for drug addiction;

- drug business as a forming and generating principle in drug addiction;

- characteristics of the domestic illicit drug market;

- Kazakhstan - as a state-transit of illegal drugs;

- personality characteristics in narcotism.

These evaluation categories and influenced the definition of structurally informative, meaningful content of scientific work.

\section{References}

Abdirov, N. M. (1996). Criminal law measures to combat drug addiction and drug business in Kazakhstan. The system and functions of law enforcement bodies of the Republic of Kazakhstan: problems and prospects. Karaganda: VSH GSK RK. 19-24.

Alexeev, A. I. (1998). Criminology. Moscow: Schit-M.

Bogolubova, T. A. (1991). Drug Addiction: The Basics of Private Criminological Theory. Moscow.

Chirkov, S. V. (2013). Some aspects of the prevention and prevention of drug addiction among minors and young people involved in drug trafficking. Legal science and practice: Bulletin of the Nizhny Novgorod Academy of the Ministry of Internal Affairs of Russia, 21, 242-246.

Data on income from the drug business. Retrieved from https:ria.ru/spravka/20100609/244280867.html 
Fetkulov, A. H., \& Mustaeva, A. M. (2017). Some issues related to the criteria for determining the size of drugs in the Republic of Kazakhstan. Monthly scientific journal "Aktual'nyye problemy gumanitarnykh $i$ yestestvennykh nauk», 2, 107-107.

Fetkulov, A. H., \& Seithozhin, B. U. (2018). Analysis of criminal law provisions providing for liability for drug trafficking without a sales target in the Republic of Kazakhstan and the Russian Federation (Article 266 of the Criminal Code of the Republic of Kazakhstan and Article 228 of the Criminal Code of the Russian Federation). Narkokontrol, 3(52), 40-43.

Fetkulov, A. H., \& Zharylkasynova, A. A. (2019). Organized crime in the field of drug trafficking in the Republic of Kazakhstan. Proceedings from XXIII International Research Competition. Penza: MTSNS "Nauka i Prosveschenie".

Gasanov, E. G. (1997). Drug addiction: trends and measures to overcome (on the materials of the Republic of Azerbaijan). Moscow: UrInfoR.

Haliullin, A. I. (2011). On the question of the relationship between the concepts of "drug addiction" and "narcotism". Bulletin of the Academy of Economic Security of the Ministry of Internal Affairs of Russia, 4, 159-162.

Harevich, D. L., \& Bazyleva, M. N. (2004). The shadow economy and the problems of the drug market. Bulletin of the Belarusian State Economic University, 6, 40-45.

Hasani Hossienabadi, M. (2016). The relationship between emotion regulations training Islamic view on betrayed women's anxiety. UCT Journal of Social Sciences and Humanities Research, 4(4), 5-9.

Hlopushin, R. (n.d.). Social control of drug addiction in the community. Retrieved from www.narcom.ru/ideas/socio/108.htm

Idinov, A. K. (2015). Drug addiction is a threat to national security. Bulletin of the Kyrgyz-Russian Slavic University, 12(15), 94-97.

Kadyrov, M. M. (1993). Problems of criminal law to combat drug trafficking. Tashkent: Uzbekistan.

Khanov, T. A., Bakischev, K. A., Fetkulov, A. H., \& Nurpeisova, A. K. (2017). General characteristics of legislative innovations in the fight against drug trafficking in the Republic of Kazakhstan. Vserossiyskiy kriminologicheskiy zhurnal, 3(11), 623-632. https://doi.org/10.17150/2500-4255.2017.11(3).623-632

Khanov, T. A., Fetkulov, A. H., \& Nurpeisova, A. K. (2014). Harmonization and unification of national legislation on the formation of the legal framework of the customs union and a single economic space. Yevraziyskiy yuridicheskiy zhurnal, 11(78), 17-21.

Kurmanov, K. Sh. (1989). Addiction: criminal law and criminological problems. Frunze: Ilim.

Law of the Republic of Kazakhstan. (1998, July 10). On narcotic drugs, psychotropic substances, their analogues and precursors and measures to counter their trafficking and abuse. Kazakhstanskaya Pravda.

Law of the Republic of Kazakhstan. (2012, January 6). On the National Security of the Republic of Kazakhstan. Retrieved from https://online.zakon.kz/Document/?doc_id=31106860\#pos $=3$

Lisetskiy, K. S., \& Lityagina, E. V. (2014). Drug addiction: the peculiarities and interrelationship of the attitude towards the disease of dependent and socially dependent. Bulletin of the Samara University. History, Pedagogy, Philology, 9(120), 251-257.

Nazarbaev, N. A. (2003). Critical decade. Almaty.

Niranjan, D. S. (2016). W.T.O. and Sugar Trade of India. Humanities \& Social Sciences Reviews, 4(1), 41-48. https://doi.org/10.18510/hssr.2016.415

Osetrov, H. V. (2015). Is it possible to defeat the drug addiction in Russia? Novaya nauka: Opyt, traditsii, innovatsii, 4(2), 73-78.

Pogrebat'ko, E. S. (2018). Drug addiction as a negative socio-legal phenomenon. Science through the prism of time, 1(10), 144-146.

Prozumentov, L. M. (2012). Drug addiction and its public danger. Scientific Bulletin of the Omsk Academy of the Ministry of Internal Affairs of Russia, 3(46), 3-6.

Redzhepov, A. E. (1985). The effectiveness of improving legislation in the fight against drug addiction. Ashkhabad. 
Sartaeva, N. A. (1998). Sociological methods in the study of the problems of drug addiction in the Republic of Kazakhstan. Karaganda.

Sbirunov, P. N. (1998). Criminological problems of combating drug trafficking in Russia. Moscow.

Shalagin, A. E. (2011). Foreign legislation in the field of countering illicit drug trafficking. Actual problems of economics and law, 4, 291-295.

Skuz, A. A., \& Kobozev, A. A. (2011). Legal and financial aspects of countering drug trafficking. Bulletin AKSOR, 3(18), 63-68.

Suhodolov, A. P., \& Bychkova, A. M. (2016). Combating drug trafficking: economic, criminological and legal $\begin{array}{lllll}\text { aspects. Vserossiyskiy 211-223. } & \text { kriminologicheskiy }\end{array}$ https://doi.org/10.17150/1996-7756.2016.10(2).211-223

Villalobos, J. V. (2018). Politics as a requirement. On the concept of Human Rights and the right to an autobiography as an ethical category. Opción, 34(85-2), 9-19.

\section{Copyrights}

Copyright for this article is retained by the author(s), with first publication rights granted to the journal.

This is an open-access article distributed under the terms and conditions of the Creative Commons Attribution license (http://creativecommons.org/licenses/by/4.0/). 